\title{
A novel synthetic trivalent single chain variable fragment (tri-scFv) construction platform based on the SpyTag/SpyCatcher protein ligase system
}

Md. Kausar Alam', Michelle Brabant ${ }^{2}$, Raja Solomon Viswas ${ }^{3}$, Kris Barreto ${ }^{1}$, Humphrey Fonge ${ }^{3}$ and C. Ronald Geyer ${ }^{1 *}$

\begin{abstract}
Background: Advances in antibody engineering provide strategies to construct recombinant antibody-like molecules with modified pharmacokinetic properties. Multermerization is one strategy that has been used to produce antibody-like molecules with two or more antigen binding sites. Multimerization enhances the functional affinity (avidity) and can be used to optimize size and pharmacokinetic properties. Most multimerization strategies involve genetically fusing or non-covalently linking antibody fragments using oligomerization domains. Recent studies have defined guidelines for producing antibody-like molecules with optimal tumor targeting properties, which require intermediates size (70-120 kDa) and bi- or tri-valency.

Results: We described a highly modular antibody-engineering platform for rapidly constructing synthetic, trivalent single chain variable fragments (Tri-scFv) using the SpyCatcher/SpyTag protein ligase system. We used this platform to construct an anti-human epidermal growth factor receptor 3 (HER3) Tri-scFv. We generated the anti-HER3 Tri-scFv by genetically fusing a SpyCatcher to the C-terminus of an anti-HER3 scFv and ligating it to a synthetic Tri-SpyTag peptide. The anti-HER3 Tri-scFv bound recombinant HER3 with an apparent $K_{D}$ of $2.67 \mathrm{nM}$, which is approximately 12 times lower than the $K_{D}$ of monomeric anti-HER3 scFv (31.2 nM). Anti-HER3 Tri-scFv also bound endogenous cell surface expressed HER3 stronger than the monomer anti-HER3 scFv.

Conclusion: We used the SpyTag/SpyCatcher protein ligase system to ligate anti-HER3 scFv fused to a SpyCatcher at its C-termini to a Tri-SpyTag to construct Tr-scFv. This system allowed the construction of a Tri-scFv with all the scFv antigen-binding sites pointed outwards. The anti-HER3 Tri-scFv bound recombinant and endogenously expressed HER3 with higher functional affinity (avidity) than the monomeric anti-HER3 scFv. The Tri-scFv had the size, valency, and functional affinity that are desired for therapeutic and imaging applications. Use of the SpyTag/ SpyCatcher protein ligase system allows Tri-scFvs to be rapidly constructed in a simple, modular manner, which can be easily applied to scFvs or other antibody fragments targeting other antigens.
\end{abstract}

Keywords: SpyTag/SpyCatcher, Multimerization, scFv, Tri-scFv, Avidity, HER3

\footnotetext{
* Correspondence: ron.geyer@usask.ca

${ }^{1}$ Department of Pathology and Laboratory Medicine, College of Medicine,

University of Saskatchewan, Room 2841, Royal University Hospital, 103

Hospital Drive, Saskatoon S7N 0W8, Canada

Full list of author information is available at the end of the article
}

(c) The Author(s). 2018 Open Access This article is distributed under the terms of the Creative Commons Attribution 4.0 International License (http://creativecommons.org/licenses/by/4.0/), which permits unrestricted use, distribution, and reproduction in any medium, provided you give appropriate credit to the original author(s) and the source, provide a link to the Creative Commons license, and indicate if changes were made. The Creative Commons Public Domain Dedication waiver (http://creativecommons.org/publicdomain/zero/1.0/) applies to the data made available in this article, unless otherwise stated. 


\section{Background}

Advances in recombinant antibody technology make it possible to produce a variety of smaller, monovalent antibody fragments, such as single-chain variable fragments (scFvs) and antigen binding fragments (Fabs) $[1,2]$, which can be cost effectively produced at high levels in bacterial expression systems. These smaller monovalent fragments have desirable pharmacokinetic properties that enable faster tumor penetration, which is desirable for imaging and therapy [3, 4]. However, monovalent fragments have decreased valency and functional affinity compared to IgGs and they lack an Fc domain, resulting in a shorter half-life and less tumor accumulation [2-4].

Imaging probes based on IgGs often show low tumor to background signaling ratios, slow clearance from blood, and slow diffusion into the tumor [2, 5-7]. The Fc domain on an IgG results in long circulation times due to its interaction with neonatal Fc receptor (FcRn) on endothelial cells and $\mathrm{pH}$-dependent recycling of IgGs back to the circulation $[8,9]$, allowing them more time to accumulate at high levels in tumors $[9,10]$. The higher background signalling of antibodies and slower tumor accumulation is driving the development of antibody fragments with better pharmacokinetics for therapy and imaging. Smaller scFvs are cleared rapidly from the circulation and have higher tumor penetration due to small size, but exhibit poor tumor retention because of their monovalent binding and lower apparent affinity $[11,12]$. Thus, new polyvalent antibody fragments are needed that possess intermediate circulation time and tumor penetration while having high functional affinity. Polyvalent antibody fragments with a size of $80-120 \mathrm{kDa}$ represent a balance between tumor penetration, target affinity, and blood clearance [13].

Computational studies comparing tumor uptake of proteins showed that tumor targeting agents around $25 \mathrm{kDa}$ have the lowest tumor uptake, whereas smaller and larger fragments have higher tumor uptake [14]. This model takes into account the difference in pharmacokinetics of different sized proteins. Smaller proteins rapidly accumulate in the tumor, but require high target affinity to be retained since they are more rapidly cleared from the blood. In contrast larger proteins require longer times to accumulate in tumors at high levels and do not require as high affinity as smaller proteins. Cuesta et al., proposed a "tumor target" zone describing features of antibody-like molecules that are required for optimal tumor targeting [13]. Key features of their model include multivalency and fragment size above the renal cutoff of $65 \mathrm{kDa}$ and below $120 \mathrm{kDa}$ to allow good tumor penetration. Antibody-like molecules that have these properties such as bivalent diabodies and minibodies [15] and trivalent trimerbodies [16, 17] have suitable biodistribution properties with good tumor uptake and high tumor to blood ratios [14, 18].

Advanced antibody engineering enables the creation of bivalent and trivalent antibody fragments that meet the tumor target zone requirements $[4,13,19]$. A number of strategies have been developed to construct trivalent antibodies with unique binding geometries, highlighting the potential to take advantage of the enhanced avidity possible with trivalent antibody fragments. Currently, strategies have been limited to genetically fused antibody fragments to generate $\mathrm{Fab}-\mathrm{scFv}_{2}$ tribodies [20] or by putting a polypeptide linker of different length to generate scFv-based tribodies [21-24]. Oligomerization domains have also been used to generate $\mathrm{scFv}$ and $\mathrm{VHH}$ based tribodies [16, 25-27].

Here, we describe a modular strategy to assemble Tri-scFvs post-translationally from scFv-SpyCatcher and Tri-SpyTag parts using the SpyTag/Catcher protein ligase system. This strategy allows smaller scFv-SpyCatcher fusion proteins to be easily and cost effectively produced in bacteria, which can be covalently ligated to a Tri-SpyTag. We used this system to produce an anti-HER3 Tri-scFv and showed that it has higher functional affinity (avidity) towards recombinant HER3 and endogenous cell surface HER3.

\section{Results}

\section{Construction of anti-HER3 tri-scFv}

We constructed the anti-HER3 Tri-scFv using the SpyTag/SpyCatcher protein ligase system [28-30] (Fig. 1a). We used a previously reported anti-HER3 $\mathrm{scFv}$ [30] and genetically fused a His-Tag-SpyCatcher to it to generate the anti-HER3 scFv-SpyCatcher construct as described previously [30]. The SpyCatcher was fused to the C-terminus of the anti-HER3 $\mathrm{scFv}$ to avoid interacting with complementarity determining regions (CDRs) in the $\mathrm{V}_{\mathrm{L}}$ and $\mathrm{V}_{\mathrm{H}}$ domains of the scFv. We expressed the anti-HER3 scFv-SpyCatcher in E. coli and used protein L chromatography to purify the anti-HER3 scFv-SpyCatcher [26]. We constructed a synthetic peptide Tri-SpyTag containing three SpyTags connected by a Gly-Gly-Ser linker (Fig. 1a).

To construct the anti-HER3 Tri-scFv (Fig. 1a), we reacted the anti-HER3 scFv-SpyCatcher $(41 \mathrm{kDa})$ with a synthetic Tri-SpyTag peptide $(4.88 \mathrm{kDa})$ at a $6: 1 \mathrm{M}$ ratio under conditions described previously [28, 30]. We used excess anti-HER3 scFv-SpyCatcher to maximize conversion of anti-HER3 Tri-scFv. We used SDS-PAGE under reducing conditions to analyze the anti-HER3 scFv-SpyCatcher and synthetic Tri-SpyTag peptide ligation reaction. Tri-scFv and SpyTag with two anti-HER3 scFv-SpyCatchers (Di-scFv) were observed at a ratio of 6:4 in the SDS-PAGE at $128 \mathrm{kDa}$ and $87 \mathrm{kDa}$, respectively (Fig. 1b). 

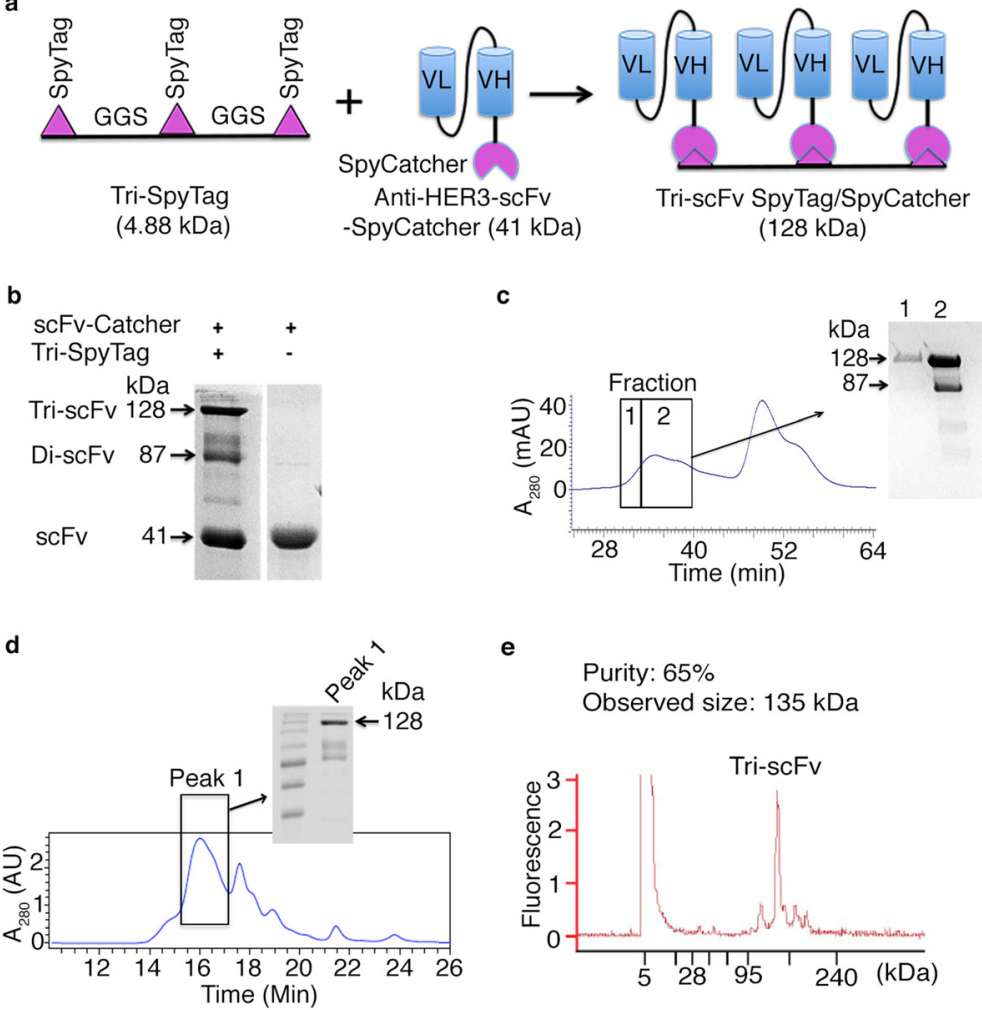

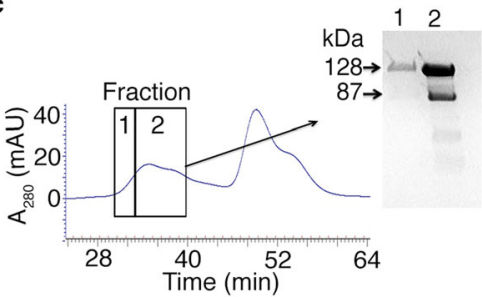

Purity: $65 \%$

Observed size: $135 \mathrm{kDa}$

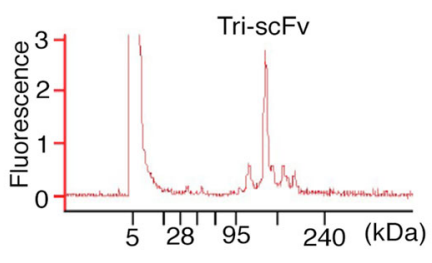

Fig. 1 Construction and Purification of SpyTag/SpyCatcher based anti-HER3 Tri-scFv. a Schematic of the SpyTag/SpyCatcher based anti-HER3 Tri-scFv ligation reaction. SpyCatcher was fused to the C-terminus of anti-HER3 scFv (VL-(G4S)3-VH-GGS-SpyCatcher). Anti-HER3 Tri-scFv was generated by mixing monomeric scFv-SpyCatcher and a synthetic Tri-SpyTag peptide together at 6:1 M ratio. VL: variable light domain, VH: variable heavy domain. b Reducing SDS-PAGE analysis of TriSpyTag peptide and scFv-SpyCatcher ligation products. scFv-SpyCatcher and Tri-SpyTag peptide have molecular weights of $41 \mathrm{kDa}$ and $4.88 \mathrm{kDa}$, respectively. After successful ligation, trivalent scFv (Tri-scFv) and divalent scFv (Di-scFv) had a molecular weight of $128 \mathrm{kDa}$ and $87 \mathrm{kDa}$, respectively. c Size-exclusion chromatogram (SEC) of Tri-scFv ligation reaction. Inset shows SDS-PAGE analysis of two fractions eluted from 30 to 40 mins. d Further separation of Tri-scFv using SEC-HPLC. Inset shows SDS-PAGE analysis of fraction eluted from 15 to 17 mins. e Bioanalyzer electropherograms of SEC-HPLC separated Tri-scFv under non-reducing conditions. The observed molecular weight (MW) of Tri-scFv is $135 \mathrm{kDa}$

\section{Anti-HER3 tri-scFv purification}

To remove excess unreacted scFv-SpyCatcher and $\mathrm{Di}-\mathrm{scFv}$ and scFv, we used size exclusion chromatography (SEC). SEC removed most of the $\mathrm{scFv}$ from Di-scFv and Tri-scFv (Fig. 1c). However, the yield of Tri-scFv after SEC was low and a significant amount of SEC fractions contained a mixture of both Tri-scFv and $\mathrm{Di}-\mathrm{scFv}$. To further separate Tri-scFv from $\mathrm{Di}-\mathrm{scF}$, we performed higher resolution SEC-HPLC (Fig. 1d). We analyzed the purity and size of SEC HPLC separated Tri-scFv using the Agilent 2100 Bioanalyzer. The final purified Tri-scFv product consisted of one major peak with a molecular mass of $135 \mathrm{kDa}$ (Fig. 1e). The final reaction yield of Tri-scFv was $\sim 20 \%$.

\section{Binding of anti-HER3 tri-scFv to recombinant HER3}

We analyzed the binding of the anti-HER3 Tri-scFv to recombinant HER3 using bio-layer interferometry. We covalently immobilized recombinant HER3 onto the sensor tip and placed the HER3-modified tip in a range of
anti-HER3 Tri-scFv and anti-HER3 scFv-SpyCatcher analyte concentrations. $K_{\mathrm{D}} \mathrm{S}$ of the anti-HER3 Tri-scFv and the anti-HER3 scFv-SpyCatcher were $2.67 \mathrm{nM}$ and $31.2 \mathrm{nM}$, respectively (Fig. 2a and c). The lower apparent $\mathrm{K}_{\mathrm{D}}$ of the anti-HER3 Tri-scFv was due to a lower $\mathrm{k}_{\text {off }}$ $\left(3.08 \mathrm{E}-04 \pm 4.80 \mathrm{E}-06 \mathrm{~s}^{-1}\right)$ versus the $\mathrm{scFv}$-SpyCatcher $\left(2.47 \mathrm{E}-03 \pm 1.57 \mathrm{E}-05 \mathrm{~s}^{-1}\right.$ ) (Fig. $2 \mathrm{a}$ and $\mathrm{c}$ ). When the anti-HER3 Tri-scFv and scFv-SpyCatcher were covalently immobilized on the sensor and immersed in a range of recombinant HER3 concentrations, the enhanced functional affinity of the anti-HER3 Tri-scFv was not observed. The $\mathrm{K}_{\mathrm{D}} \mathrm{s}$ of Tri-scFv and scFv-SpyCatcher were $14.3 \mathrm{nM}$ and $16.9 \mathrm{nM}$, respectively (Fig. $2 \mathrm{~b}$ and c). Since the HER3 analyte was monovalent, we would not expect to observe any avidity against biosensor immobilized scFv or tri-scFv.

The results do not confirm that the avidity is due to engagement of all three scFvs to HER3 at the same time. Previous studies showed that an anti-HER3 IgG and a bivalent $\mathrm{scFv}$ generated with the same anti-HER3 $\mathrm{scFv}$ 
$a_{i}$

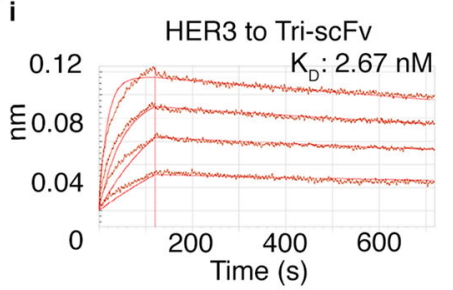

b.

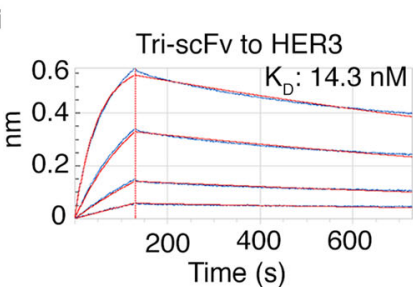

$\mathbf{c}_{\mathrm{i}}$

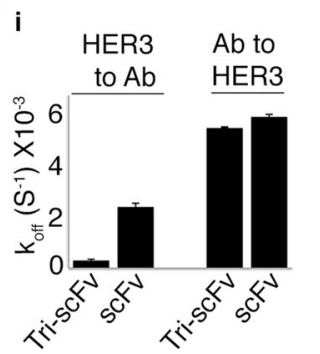

ii

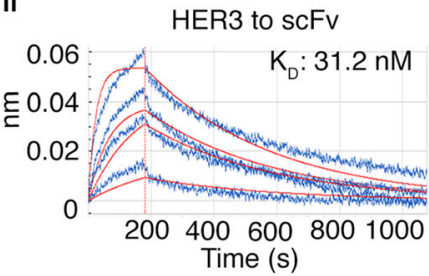

ii

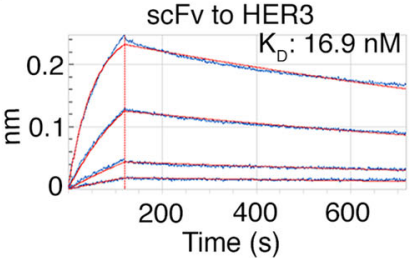

d

ii HER3

\section{Ab to}

iii

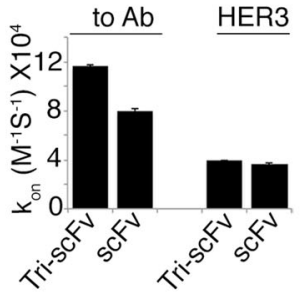

iii HER3 Ab to
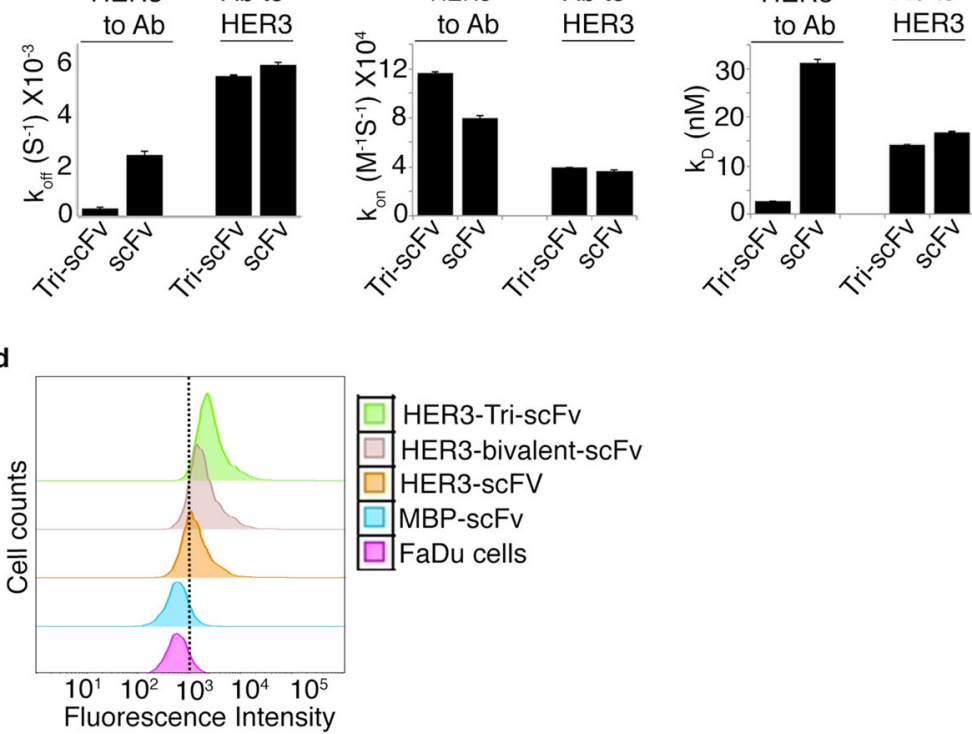

Fig. 2 Analysis of the HER3 binding Tri-scFv and monomeric scFv-SpyCatcher to recombinant HER3 and a HER3-postive cell line. Biolayer interferometry kinetic analysis of anti-HER3 Tri-scFv and anti-HER3 scFv-SpyCatcher against recombinant HER3. a HER3 sensors were generated by covalently immobilizing HER3 on AR2G sensors. HER3 sensors were placed in wells containing concentrations of Anti-HER3 Tri-scFv (i) and anti-HER3 scFv-SpyCatcher (ii), ranging from 20 nM to 500 nM. b anti-HER3 Tri-scFv and anti-HER3 scFv-SpyCatcher sensors were generated by covalently immobilizing Anti-HER3 Tri-scFv (i) and anti-HER3 scFv-SpyCatcher (ii) on AR2G sensors. Tri-scFv and monomeric scFv loaded sensors were then placed in wells containing concentrations of HER3, ranging from $20 \mathrm{nM}$ to $500 \mathrm{nM}$. c Comparison of $\mathrm{k}_{\text {off }}$ (i), $\mathrm{k}_{\text {on }}$ (ii), and $\mathrm{K}_{\mathrm{D}}$ (iii) between anti-HER3 Tri-scFv and scFv-SpyCatcher with HER3 using HER3 and scFv sensors. Data analysis and fitting were performed using ForteBio's Data analysis software version 8.1. Error bars represent the percentage of fitting error as calculated by FortéBio Data Analysis software. $\mathbf{d}$ Flow cytometry analysis of binding of anti-HER3 Tri-scFv and scFv-SpyCatcher to the HER3-positive FaDu cell line. A fixed concentration (0.5 $\mu \mathrm{M})$ of IRDye680RD-labeled anti-HER3 Tri-scFv-IRDye680 (HER3 Tri-scFv) and anti-HER3 scFv-SpyCatcher-IRDye680 (HER3-scFv) were incubated with $1 \times 10^{5} \mathrm{FaDu}$ cells. Anti-Maltose Binding Protein scFv-SpyCatcher-680 (MBP scFv-SpyCatcher) was used a negative control. The mean fluorescent intensity (MFI) was 592 for FaDu cells, 696 for the MBP-scFv, 3834 for the scFv, 4636 for the bivalent-scFv, and 6919 for the Tri-scFv. The Labeling efficiency of the Tri-scFv-IRDye680, bivalent-scFv-IRDye680, scFv-SpyCatcher-IRDye680 and MBP-scFv-IRDye680 was 2.1, 1.7, 1.6, and 1.5 dyes per antibody fragment, respectively

using the spyTag/SpyCatcher systems [30] have a apparent $\mathrm{K}_{\mathrm{D}} \mathrm{s}$ of $6 \mathrm{nM}$ and $7.01 \mathrm{nM}$, respectively, which were between the Tri-scFv $(2.67 \mathrm{nM})$ and the $\mathrm{scFv}(31.2 \mathrm{nM})$. The major difference between the scFv, bivalent-scFv, IgG, and Tri-scFv was lower $\mathrm{K}_{\text {off }} \mathrm{S}$, which were 2.47E-03 $\mathrm{s}^{-1}$,
6.90E-04 s ${ }^{-1}, 6.01 \mathrm{E}-04 \mathrm{~s}^{-1}$, and 3.08E-04 $\mathrm{s}^{-1}$, respectively. Although anti-HER3 scFvs in the polyvalent fragments may not be optimally arranged to allow simultaneous engagement, the addition of scFvs to antibody fragments results in lower $\mathrm{k}_{\mathrm{off}} \mathrm{s}$. 


\section{Binding of anti-HER3 tri-scFv to endogenous cell surface HER3}

We used flow cytometry to compare the binding of anti-HER3 Tri-scFv, bivalent-scFv [30], and scFvSpyCatcher to the HER3-positive FaDu cell line (Fig. 2d). We labeled anti-HER3 Tri-scFv, bivalent-scFV, and scFv-SpyCatcher with IRDye680RD NHS ester. Previously, we showed that labeling of an anti-HER3 antibody fragments consisting of the same light and heavy variable domains with IRDye800CW-NHS ester did not inhibit binding to the FaDu cells [In Press]. FaDu cells $\left(1 \times 10^{5}\right)$ were labeled with anti-HER3 Tri-scFv, bivalent-scFv, and monomeric scFv-SpyCatcher at a fixed concentration $(0.5 \mu \mathrm{M})$. An IRDye680RD labeled anti-Maltose Binding Protein scFv-SpyCatcher (anti-MBP scFv-SpyCatcher) was used as a negative control for flow cytometry analyses. The anti-HER3 Tri-scFv labeled FaDu cells with a mean fluorescence intensity (MFI) of 6919, followed by the bivalent-scFv (MFI -4636) and the ScFv (MFI -3834), which was consistent with the trend observed for recombinant HER3 binding.

\section{Discussion}

In this study, we used the SpyTag/SpyCatcher protein ligase system [28-30] to construct an anti-HER3 Tri-scFv with increased size and valency relative to the anti-HER3 scFv. The spyTag/SpyCatcher ligase is active under a variety of reaction conditions and forms an irreversible isopeptide bond [28]. The anti-HER3 Tri-scFv showed a lower $K_{D}$ due to a slower $k_{\text {off }}$ against recombinant HER3 than the anti-HER3 scFv, consistent with enhanced avidity of the anti-HER3 Tri-scFv. The MFI of anti-HER3 Tri-scFv stained cells expressing endogenous cell surface HER3 was 2.4-fold higher than anti-HER3 $\mathrm{scFv}$ at the $0.5 \mu \mathrm{M}$ concentration tested.

Antibody fragments with trivalency have been identified as ideal reagents for rapid tumor retention [13, 15-18]. Current methods to generate trivalent antibody fragments use flexible polypeptide linkers [21-24], linear gene fusions [20], or self-associating peptides [16, 25-27]. Genetically fusing fragments limits the orientation of fragments and requires the expression and correct folding of larger antibody fragments. Flexible linkers that drive formation of trivalent antibody fragment or the use of oligomerization domains to non-covalently associate fragments result in antibody fragments that are heterogeneous in nature [21-24]. In comparison, the SpyTag/ SpyCatcher protein ligase system allows greater flexibility in joining antibody fragments. The SpyCatcher domain can be used as a $\mathrm{N}$ - or C-termini fusion and the SpyTag peptide can be inserted at the $\mathrm{N}$ - or C-termini or in the middle of the antibody fragment [28-31]. In the Tri-scFv, the SpyCatcher domain was fused to the $\mathrm{C}$-terminus to the $\mathrm{scFv}$ so the scFv could be post-translationally conjugated to the SpyTag at a site distant from the CDRs. These types of linkages are not possible by genetically fusing the scFvs together.

Further optimization of the Tri-scFv reaction is required as the yield is relatively low $(\sim 20 \%)$ and requires high resolution high SEC-HPLC to remove $\mathrm{Di}-\mathrm{scFv}$ product. Optimization of the space between the SpyTags in the Tri-SpyTag-peptide may remove possible steric hindrance between scFvs and improve yields. More space between the SpyTags would also provide more flexibility to the Tri-scFv, resulting in better binding by making it easier for scFvs to simultaneously engage HER receptors.

\section{Conclusion}

We demonstrated a modular system to post-translationally assemble synthetic scFvs to generate a trivalent Tri-scFv. The system uses pre-constructed antibody fragments genetically fused to the SpyCatcher domain and a synthetic peptide encoding three sequential SpyTag moieties. The system is universal in that in can be used with a variety of antibody fragments to antibody-like molecules with high valency. The system is cost-effective as many small fragments can be produced in bacteria and SpyTags can be constructed using solid-phase peptides synthesis.

\section{Methods}

\section{Tri-SpyTag}

Tri-SpyTag was purchased from Genscript (GenScript, New Jersey, USA). TriSpyTag sequence is: AHIVMVDAYKPTKGGSAHIVMVDAYKPTKGGSAHIVMVDAYK PTKC.

\section{Anti-HER3 mono-scFv-SpyCatcher expression and purification}

The expression plasmid, pCW-Anti-HER3-scFv-Catcher-His $_{6}$ [30] was generated by inserting SpyCatcher-His at the C-terminus of $\mathrm{V}_{\mathrm{H}}$ of $\mathrm{scFv}$ as described previously [30]. Anti-HER3 scFv-SpyCatcher expression plasmid was transformed into BL21 (DE3) competent E. coli cells (NEB) and plated on $2 \mathrm{YT}$ media containing antibiotic carbenicillin. Single E. coli colonies were cultured in overnight expression Instant $\mathrm{TB}$ media (Novagen) for 20-24 h. Cells were pelleted and suspended in Protein L Binding buffer (Sodium Phosphate $20 \mathrm{mM}, 0.15 \mathrm{M}$ $\mathrm{NaCl}, \mathrm{pH}$ 8.0). Cells were disrupted at $35 \mathrm{Kpsi}$ using the Cell disruptor (Constant System LTD. USA). Cell debris was removed by centrifuging at 12,000 RPM for $20 \mathrm{~min}$. Supernatant was collected and filtered through a $0.45-\mu \mathrm{m}$ membrane filter (Minisart, Sartorius stedim). Anti-HER3 mono-scFv-SpyCatcher was purified on a GE Healthcare AKTA FPLC system using a HiTrap Protein L column (GE Heathcare). Anti-HER3 mono-scFv-SpyCatcher was 
eluted from the Protein L column using IgG elution buffer (Fisher Scientific) and neutralized with neutralization buffer (1 M Tris-HCl pH 9.0). Purified Anti-HER3 mono-scFv-SpyCatcher was dialyzed overnight in PBS and concentrated using $10 \mathrm{~K}$ MWCO filter (Millipore). Anti-HER3 mono-scFv-SpyCatcher was filter sterilized and stored at $-20^{\circ} \mathrm{C}$. Anti-HER3 mono-scFv-SpyCatcher was quantified using the Bicinchonic acid assay (Pierce ${ }^{\mathrm{Tx}}$ BCA Protein Assay Kit, Thermo Scientific) following manufacturer's instructions.

\section{Generation of tri-scFv}

Anti-HER3-TriscFv was synthesized by reacting anti-HER3 scFv-SpyCatcher-His $_{6}\left(\begin{array}{lll}60 & \mu \mathrm{M}\end{array}\right)$ with the Tri-SpyTag $(10 \mu \mathrm{M})$ for $4 \mathrm{~h}$ at room temperature in phosphate-citrate buffer $\mathrm{pH} 7$, as describe previously [28-30].

\section{SDS-page}

Purified antibody fragments were separated under reducing conditions on $12 \%$ SDS PAGE. Proteins were stained with Coomassie blue and visualized using GelDoc $\mathrm{XR}^{+}$system (BioRad). Ratios of Tri-scFv and Di-scFv were calculated using Image J Browser (Image) $1.49 \mathrm{~V})$.

\section{Size exclusion chromatography (SEC)}

Conjugated anti-HER3 Tri-scFv reaction was separated using the HiLoad $^{\mathrm{mm}}$ 16/600 Superdex ${ }^{\mathrm{ma}} 200$ pg (GE Healthcare). The gel filtration column was equilibrated with PBS pH 7.4. Anti-HER3 Tri-scFv $(5 \mathrm{ml})$ was subjected to size-exclusion chromatography at flow-rates of $1 \mathrm{~mL} / \mathrm{min}$ on the AKTA Prime FPLC system (GE Healthcare).

\section{Size exclusion HPLC}

SEC separated peak of anti-HER3 Tri-scFv was separated

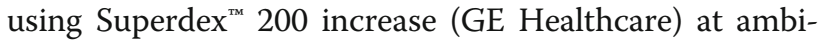
ent temperature by using HPLC Bio-separation system (Waters). The gel filtration column was equilibrated with PBS $\mathrm{pH}$ 7.4. The separation was performed at $0.6 \mathrm{~mL} /$ min flow rate for 30 min by using a mobile phase containing PBS, $\mathrm{pH}$ 7.0. The absorbance at 220 and $280 \mathrm{~nm}$ of the eluate was monitored during the LC run.

\section{Agilent 2100 bioanalyzer}

The molecular weight (MW) and purity of the anti-HER3 Tri-scFv was determined using the Agilent 2100 Bioanalyzer using Agilent High Sensitivity Protein 250 Kit (cat \# 5067-1575) according to manufacture's conditions. Briefly, Anti-HER3 Tri-scFv $(0.5 \mathrm{mg} / \mathrm{mL})$ was labeled with a fluorescent dye at non-reducing condition as described in the High Sensitivity Protein 250 kit guide. The chip preparation was performed according to the manual provided with the kit. Samples were then separated in the chip and detected using a fluorescence detector. The molecular weight and peak areas were calculated using Agilent 2100 Expert software.

\section{Biolayer interferometry}

On $\left(\mathrm{k}_{\mathrm{on}}\right)$ and off $\left(\mathrm{k}_{\text {off }}\right)$ rates for the anti-HER3 mono-scFv-SpyCatcher and the anti-HER3 Tri-scFv with recombinant HER3 was measured using biolayer interferometry with the ForteBio Octet ${ }^{\text {Red }} 384$ and AR2G sensors, according to manufacturer's conditions. Briefly, biolayer interferometry procedures were performed at $30{ }^{\circ} \mathrm{C}$ with shaking at $1000 \mathrm{rpm}$. For HER3 to antibody, AR2G sensors were loaded with recombinant HER3 (Sino Biological) by incubating AR2G sensors in $50 \mu \mathrm{L}$ of HER3 (500 nM) for $300 \mathrm{~s}$. HER3 loaded sensors were washed in PBS for $300 \mathrm{~s}$ and then placed in wells containing a range of anti-HER3 mono-scFv-SpyCatcher and anti-HER3 Tri-scFv concentrations, ranging from $20 \mathrm{nM}$ to $500 \mathrm{nM}$. For biolayer interferometry in the reverse orientation, AR2G sensors were loaded with anti-HER3 monoscFv-SpyCatcher and anti-HER3 Tri-scFv by incubating AR2G sensors in $50 \mu \mathrm{L}$ of antibody fragments $(500 \mathrm{nM})$ for $300 \mathrm{~s}$. Antibody fragment loaded sensors were washed in PBS for $300 \mathrm{~s}$ and then placed in wells containing a range of recombinant HER3 concentrations, ranging from $20 \mathrm{nM}$ to $500 \mathrm{nM}$. Rates of association were monitored for $5 \mathrm{~min}$ and rates of dissociation were monitored for $10 \mathrm{~min}$. Data analysis and fitting were performed using ForteBio's Data analysis software version 8.1. We used a 1:1 binding model to fit the data, which is commonly used for kinetics analysis of monoclonal antibodies (IgG) to antigen [32]. Previous instances have shown that $K_{D} S$ were similar for both 1:1 and 2:1 models, with a worse fit but more accurate data obtained with the 1:1 model https://www.fortebio.com/ interactions/Fall_2014/index2.html.

\section{Tissue culture}

The HER3 positive human head and neck squamous cell carcinoma cell line, FaDu cell line, was obtained from ATCC (Rockville, MD, USA) [33]. FaDu cells were propagated by serial passage in MEM/EBSS medium (HyClone Laboratories, Logan UT), supplemented with $10 \%$ fetal bovine serum (FBS) at $37{ }^{\circ} \mathrm{C}$ in a humidified atmosphere of $5 \% \mathrm{CO}_{2}$.

\section{Labeling of anti-HER3 scFv-SpyCatcher and anti-HER3 tri-scFv with IRDye680RD NHS ester}

IRDye680RD NHS ester (LI-COR Biosciences Co., Lincoln, $\mathrm{NE)}$ was used to label anti-HER3 scFv-SpyCatcher and anti-HER3 Tri-scFv. A total of $0.5 \mathrm{mg}$ of Anti-HER3 scFv-SpyCatcher and Anti-HER3 Tri-scFv in $0.5 \mathrm{~mL}$ phosphate-buffered saline (PBS, pH 7.4) was labeled with 3 -fold molar excess of IRDye 680RD-NHS ester by mixing 
and rotating for $2 \mathrm{~h}$ at room temperature protected from light followed by rotating overnight at $4{ }^{\circ} \mathrm{C}$. The reaction was quenched with molar excess of pure Tris base. The dye to protein ratio was determined by measuring the labeled protein absorbance in PBS at $280 \mathrm{~nm}$ and $774 \mathrm{~nm}$ as per the manufacturer's recommendation [34]. The labeled anti-HER3 mono-scFv-SpyCatcher and antiHER3 Tri-scFv were store at $-20{ }^{\circ} \mathrm{C}$ for further use.

\section{Flow cytometry}

The binding of anti-HER3 mono-scFv-SpyCatcher and anti-HER3 Tri-scFv to Fadu cells was analyzed by flow cytometry. $1 \times 10^{5}$ cells/tube were incubated with $50 \mu \mathrm{M}$ of anti-HER3 monoscFv-SpyCatcher-IRDye680 or anti-HER3 Tri-scFv-IRDye680 at room temperature for 60 mins. Cells were washed three times with PBS, pH 7.4. Flow cytometry was performed using a Beckman Coulter Gallios flow cytometer system with $680 \mathrm{~nm}$ excitation and $694 \mathrm{~nm}$ emission wavelengths. Data obtained was analyzed using FlowJo (Tree Star).

\section{Abbreviations}

AR2G: Amine reactive second-generation; Di-ScFv: Divalent Single chain variable fragments; EC: Effective concentration; HER3: Epidermal growth factor receptor 3; HPLC: High Performance Liquid Chromatography; MonoscFv: Monovalent Single chain variable fragments; scFv: Single chain variable fragments; SDS-PAGE: sodium dodecyl sulfate polyacrylamide gel electrophoresis; SEC: Size exclusion chromatography; Tri-scFv: Trivalent Single chain variable fragments

\section{Acknowledgements}

We thank Wayne Hill and Carolina Gonzalez for their assistance during BLI kinetic assay and Bio-analyzer experiment respectively. We thank Dr. Ayman El-Sayed for providing pCW-Anti-HER3-scFv plasmid.

\section{Funding}

Funding for the study was provided by Western Economic Diversification Canada \#12939, Fedoruk Centre \# J2014-0025. The funding bodies were not involved in the design of the study and collection, analysis, and interpretation of data or in writing the manuscript.

\section{Availability of data and materials}

The datasets used and/or analyzed during the current study available from the corresponding author upon a reasonable request.

\section{Authors' contributions}

KA designed and performed cloning, purification, SEC, Flow cytometry experiments, prepared sample for BLI \& Bio-analyzer, analyzed data and co-wrote the manuscript. MB performed purification, conjugation and SEC experiments and assisted in performing BLI, Bio-analyzer, and Flow cytometry experiments. RSV performed HPLC experiments. K.B. analyzed data and edited manuscript, HF helped supervise the study, reviewed and edited the manuscript. CRG designed experiments, supervised the study, and wrote the manuscript. All authors have read and approved the manuscript.

\section{Ethics approval and consent to participate}

Not applicable.

\section{Consent for publication}

Not applicable.

\section{Competing interests}

The authors declare that they have no competing interests.

\section{Publisher's Note}

Springer Nature remains neutral with regard to jurisdictional claims in published maps and institutional affiliations.

\section{Author details}

'Department of Pathology and Laboratory Medicine, College of Medicine, University of Saskatchewan, Room 2841, Royal University Hospital, 103 Hospital Drive, Saskatoon S7N 0W8, Canada. ${ }^{2}$ Department of Biochemistry, College of Medicine, University of Saskatchewan, Saskatoon, SK S7N 5E5, Canada. ${ }^{3}$ Medical Imaging, University of Saskatchewan, Saskatoon, SK S7N 5E5, Canada.

Received: 15 June 2018 Accepted: 3 September 2018 Published online: 10 September 2018

References

1. Ayyar BV, Arora S, Ravi SS. Optimizing antibody expression: the nuts and bolts. Methods. 2017;116:51-62.

2. Holliger P, Hudson PJ. Engineered antibody fragments and the rise of single domains. Nat Biotechnol. 2005:23:1126-36.

3. Adams GP, Schier R, McCall AM, Simmons HH, Horak EM, Alpaugh RK, Marks JD, Weiner LM. High affinity restricts the localization and tumor penetration of single-chain Fv antibody molecules. Cancer Res. 2001;61:4750-5.

4. Brekke $\mathrm{OH}$, Løset GÅ. New technologies in therapeutic antibody development. Curr Opin Pharmacol. 2003;3:544-50.

5. Kovar JL, Simpson MA, Schutz-Geschwender A, Olive DM. A systematic approach to the development of fluorescent contrast agents for optical imaging of mouse cancer models. Anal Biochem. 2007;367:1-12.

6. Terwisscha van Scheltinga AG, van Dam GM, Nagengast WB, Ntziachristos $V$, Hollema H, Herek JL, Schröder CP, Kosterink JG, Lub-de Hoog MN, de Vries EG. Intraoperative nearinfrared fluorescence tumor imaging with vascular endothelial growth factor and human epidermal growth factor receptor 2 targeting antibodies. J Nucl Med. 2011:52:1778-85.

7. Olafsen T, Wu AM. Antibody vectors for imaging. Semin Nucl Med. 2010;40:167-81.

8. Zalevsky J, Chamberlain AK, Horton HM, Karki S, Leung IW, Sproule TJ, Lazar GA, Roopenian DC, Desjarlais JR. Enhanced antibody half-life improves in vivo activity. Nat Biotechnol. 2010;28:157-9.

9. Beck A, Reichert JM. Therapeutic fc-fusion proteins and peptides as successful alternatives to antibodies. MAbs. 2011;3:415-6.

10. Chames P, Van Regenmortel M, Weiss E, Baty D. Therapeutic antibodies: successes, limitations and hopes for the future. Br J Pharmaco. 2009;157:220-33.

11. Todorovska A, Roovers RC, Dolezal O, Kortt AA, Hoogenboom HR, Hudson PJ. Design and application of diabodies, triabodies and tetrabodies for cancer targeting. J Immunol Methods. 2001;248:47-66.

12. Wu AM, Chen W, Raubitschek A, Williams LE, Neumaier M, Fischer R, Hu SZ, Odom-Maryon T, Wong JY, Shively JE. Tumor localization of anti-CEA singlechain Fvs: improved targeting by non-covalent dimers. Immunotechnology. 1996;2:21-36.

13. Cuesta ÁM, Sainz-Pastor N, Bonet J, Oliva B, Álvarez-Vallina L. Multivalent antibodies: when design surpasses evolution. Trends Biotechnol. 2010;28:355-62.

14. Schmidt MM, Wittrup KD. A modeling analysis of the effects of molecular size and binding affinity on tumor targeting. Mol Cancer Ther. 2009;8:286171

15. Hu SZ, Shively L, Raubitschek A, Sherman M, Williams LE, Wong JY, Shively $J E$, Minibody WAM. A novel engineered anti-carcinoembryonic antigen antibody fragment (single-chain Fv-C H 3) which exhibits rapid, high-level targeting of xenografts. Cancer Res. 1996;56(13):3055-61.

16. Cuesta AM, Sánchez-Martín D, Sanz L, Bonet J, Compte M, Kremer L, Blanco FJ, Oliva B, Álvarez-Vallina L. In vivo tumor targeting and imaging with engineered trivalent antibody fragments containing collagen-derived sequences. PLoS One. 2009;4:e5381.

17. Spiess C, Zhai Q, Carter PJ. Alternative molecular formats and therapeutic applications for bispecific antibodies. Mol Immunol. 2015;67:95-106.

18. Williams LE, Wu AM, Yazaki PJ, Liu A, Raubitschek AA, Shively JE, Wong JY Numerical selection of optimal tumor imaging agents with application to engineered antibodies. Cancer Biother Radiopharm. 2001;16(1):25-35.

19. Little M, Kipriyanov SM, Le Gall F, Moldenhauer G. Of mice and men: hybridoma and recombinant antibodies. Immunol Today. 2000;21:364-70. 
20. Mertens N. Tribodies: fab-scfv fusion proteins as a platform to create multifunctional pharmaceuticals. In: Bispecific Antibodies: Springer Berlin Heidelberg; 2011. p. 135-49.

21. Nuñez-Prado N, Compte M, Harwood S, Álvarez-Méndez A, Lykkemark S, Sanz L, Álvarez-Vallina L. The coming of age of engineered multivalent antibodies. Drug Discov Today. 2015;20:588-94.

22. Dolezal O, Pearce LA, Lawrence LJ, McCoy AJ, Hudson PJ, Kortt AA. SCFV multimers of the anti-neuraminidase antibody NC10: shortening of the linker in single-chain Fv fragment assembled in $\mathrm{V}(\mathrm{L})$ to $\mathrm{V}(\mathrm{H})$ orientation drives the formation of dimers, trimers, tetramers and higher molecular mass multimers. Protein Eng. 2000;13:565-74.

23. Power BE, Doughty L, Shapira DR, Burns JE, Bayly AM, Caine JM, Liu Z, Scott AM, Hudson PJ, Kortt AA. Noncovalent scFv multimers of tumor-targeting anti-Lewis(y) hu3S193 humanized antibody. Protein Sci. 2003;12:734-47.

24. Blanco-Toribio A, Sainz-Pastor N, Álvarez-Cienfuegos A, Merino N, Cuesta ÁM, Sánchez-Martín D, Bonet J, Santos-Valle P, Sanz L, Oliva B, Blanco FJ. Generation and characterization of monospecific and bispecific hexavalent trimerbodies. MAbs. 2013;5:70-9.

25. Sánchez-Arévalo Lobo VJ, Cuesta ÁM, Sanz L, Compte M, García P, Prieto J, Blanco FJ, Álvarez-Vallina L. Enhanced antiangiogenic therapy with antibody-collagen XVIII NC1 domain fusion proteins engineered to exploit matrix remodeling events. Int J Cancer. 2006;119:455-62.

26. Cuesta ÁM, Sánchez-Martín D, Blanco-Toribio A, Villate M, Enciso-Álvarez K, Alvarez-Cienfuegos A, Sainz-Pastor N, Sanz L, Blanco FJ, Álvarez-Vallina L. Improved stability of multivalent antibodies containing the human collagen XV trimerization domain. MAbs. 2012:4:226-32.

27. Willuda J, Kubetzko S, Waibel R, Schubiger PA, Zangemeister-Wittke U, Pluckthun A. Tumor targeting of mono-, di-, and tetravalent anti-p185(HER-2) miniantibodies multimerized by self-associating peptides. J Biol Chem. 2001;276:14385-92.

28. Zakeri B, Fierer JO, Celik E, Chittock EC, Schwarz-Linek U, Moy VT, Howarth M. Peptide tag forming a rapid covalent bond to a protein, through engineering a bacterial adhesin. Proc Natl Acad Sci U S A. 2012;109:690-7.

29. Li L, Fierer JO, Rapoport TA, Howarth M. Structural analysis and optimization of the covalent association between SpyCatcher and a peptide tag. J Mol Biol. 2014;426:309-17.

30. Alam MK, Gonzalez C, Hill W, El-Sayed A, Fonge H, Barreto K, Geyer CR. Synthetic modular antibody construction using the SpyTag/SpyCatcher protein ligase system. Chembiochem. 2017; https://doi.org/10.1002/cbic. 201700411.

31. Yumura K, Akiba H, Nagatoishi S, Kusano-Arai O, Iwanari H, Hamakubo T, Tsumoto K. Use of SpyTag/SpyCatcher to construct bispecific antibodies that target two epitopes of a single antigen. J Biochem. 2017;162:203-10.

32. Yang $D$, Singh A, Wu H, Kroe-Barrett R. Comparison of biosensor platforms in the evaluation of high affinity antibody-antigen binding kinetics. Anal Biochem. 2016;508:78-96

33. Wilson TR, Lee DY, Berry L, Shames DS, Settleman J. Neuregulin-1-mediated autocrine signaling underlies sensitivity to HER2 kinase inhibitors in a subset of human cancers. Cancer Cell. 2011;20:158-72.

34. Oliveira S, Van Dongen GA, Stigter-Van Walsum M, Roovers RC, Stam JC, Mali W, van Diest PJ, Van Bergen en Henegouwen PM. Rapid visualization of human tumor xenografts through optical imaging with a near-infrared fluorescent anti- epidermal growth factor receptor Nanobody. Mol Imaging. 2012;11:33-46

\section{Ready to submit your research? Choose BMC and benefit from:}

- fast, convenient online submission

- thorough peer review by experienced researchers in your field

- rapid publication on acceptance

- support for research data, including large and complex data types

- gold Open Access which fosters wider collaboration and increased citations

- maximum visibility for your research: over $100 \mathrm{M}$ website views per year

At $\mathrm{BMC}$, research is always in progress.

Learn more biomedcentral.com/submissions 